\title{
Risk factors for prolonged length of stay after the stage 2 procedure in the single-ventricle reconstruction trial
}

\author{
Steven M. Schwartz, MD, ${ }^{\mathrm{a}}$ Minmin Lu, MS, ${ }^{\mathrm{b}}$ Richard G. Ohye, MD, ${ }^{\mathrm{c}}$ Kevin D. Hill, MD, ${ }^{\mathrm{d}}$ \\ Andrew M. Atz, MD, ${ }^{\mathrm{e}}$ Maryam Y. Naim, MD,${ }^{\mathrm{f}}$ Ismee A. Williams, MD, MS, ${ }^{\mathrm{g}}$ Caren S. Goldberg, MD, MS, ${ }^{\mathrm{h}}$ \\ Alan Lewis, MD ${ }^{\mathrm{i}}$ Frank Pigula, MD,${ }^{\mathrm{j}}$ Peter Manning, MD, ${ }^{\mathrm{k}}$ Christian Pizarro, MD, ${ }^{\mathrm{l}}$ Paul Chai, MD, ${ }^{\mathrm{m}}$ \\ Rachel McCandless, MD, ${ }^{\mathrm{n}}$ Carolyn Dunbar-Masterson, BSN ${ }^{\circ}$ Jonathan R. Kaltman, MD, ${ }^{\mathrm{p}}$ \\ Kirk Kanter, MD, ${ }^{\mathrm{q}}$ Lynn A. Sleeper, ScD, ${ }^{\mathrm{b}}$ Julie V. Schonbeck, MSN, C-PNP, ${ }^{\mathrm{b}}$ and Nancy Ghanayem, MD, ${ }^{\mathrm{r}}$ \\ for the Pediatric Heart Network Investigators
}

Background: The single-ventricle reconstruction trial randomized patients with single right ventricle lesions to a modified Blalock-Taussig or right ventricle-to-pulmonary artery shunt at the Norwood. This analysis describes outcomes at the stage 2 procedure and factors associated with a longer hospital length of stay (LOS).

Methods: We examined the association of shunt type with stage 2 hospital outcomes. Cox regression and bootstrapping were used to evaluate risk factors for longer LOS. We also examined characteristics associated with in-hospital death.

Results: There were 393 subjects in the analytic cohort. Median stage 2 procedure hospital LOS ( 8 days;
interquartile range $[\mathrm{IQR}], 6-14$ days), hospital mortality $(4.3 \%)$, transplantation $(0.8 \%)$, median ventilator
time ( 2 days; IQR, $1-3$ days), median intensive care unit $\mathrm{LOS}(4$ days; IQR, $3-7$ days), number of additional
cardiac procedures or complications, and serious adverse events did not differ by shunt type. Longer LOS
was associated $\left(\mathrm{R}^{2}=0.26\right)$ with center, longer post-Norwood LOS (hazard ratio $[\mathrm{HR}], 1.93$ per log day;
$P<.001)$, nonelective timing of the stage 2 procedure (HR, $1.78 ; P<.001)$, and pulmonary artery (PA) stenosis
$(\mathrm{HR}, 1.56 ; P<.001)$. By univariate analysis, nonelective stage $2(65 \%$ vs $32 \% ; P=.009)$, moderate or greater
atrioventricular valve (AVV) regurgitation ( $75 \%$ vs $24 \% ; P<.001)$, and AVV repair $(53 \%$ vs $9 \% ; P<.001)$
were among the risk factors associated with in-hospital death.

Conclusions: Norwood LOS, PA stenoses, and nonelective stage 2 procedure, but not shunt type, are independently associated with longer LOS. Nonelective stage 2 procedure, moderate or greater AVV regurgitation, and need for AVV repair are among the risk factors for death. (J Thorac Cardiovasc Surg 2014;147:1791-8)

Supplemental material is available online.

Staged surgical repair for hypoplastic left heart syndrome (HLHS) and other single right ventricle anomalies usually

\footnotetext{
From the Divisions of Cardiac Critical Care Medicine and Cardiology, ${ }^{a}$ Departments of Critical Care Medicine and Paediatrics, The Hospital for Sick Children, Toronto, Ontario, Canada; New England Research Institutes, ${ }^{\mathrm{b}}$ Watertown, Mass; Division of Pediatric Cardiovascular Surgery, ${ }^{\mathrm{c}}$ Department of Cardiac Surgery, and Division of Pediatric Cardiology, ${ }^{\mathrm{h}}$ Department of Pediatrics \& Communicable Diseases, University of Michigan Medical School, Ann Arbor, Mich; Division of Cardiology, ${ }^{\mathrm{d}}$ Department of Pediatrics, Duke University, Durham, NC; Division of Pediatric Cardiology, ${ }^{\mathrm{e}}$ Department of Pediatrics, Medical University of South Carolina, Charleston, SC; Division of Critical Care Medicine, ${ }^{\mathrm{f}}$ Department of Anesthesia and Critical Care, Children's Hospital of Philadelphia, Philadelphia, Pa; Division of Pediatric Cardiology, ${ }^{\mathrm{g}}$ Department of Pediatrics, Columbia University, New York, NY; Division of Cardiology, ${ }^{\mathrm{i}}$ Department of Pediatrics, Children's Hospital Los Angeles, Los Angeles, Calif; Department of Cardiac Surgery ${ }^{j}$ and Department of Cardiology, ${ }^{\circ}$ Children's Hospital Boston, Boston, Mass; Division of Cardiovascular Surgery, ${ }^{k}$ Department of Surgery, Cincinnati Children's Hospital Medical Center, Cincinnati, Ohio; Division of Pediatric Cardiothoracic Surgery, ${ }^{1}$ Department of Surgery, Alfred I. duPont Hospital for Children, Wilmington, Del; Division of Cardiovascular Surgery, ${ }^{\mathrm{m}}$ All Children's Hospital, Tampa, Fla; Division of Pediatric Cardiology, ${ }^{\mathrm{n}}$ Department of Pediatrics, Primary Children's Medical Center, Salt Lake City, Utah; Heart Development and Structural Diseases Branch, ${ }^{\mathrm{p}}$
}

includes a stage 2 procedure (superior cavopulmonary connection) between the Norwood and Fontan procedures (total cavopulmonary connection). This approach reduces morbidity and mortality at the time of the Fontan procedure $^{1,2}$ and is well tolerated. Several series suggest the median length of hospital stay (LOS) is 5 to 7 days and

Division of Cardiovascular Sciences, National Heart, Lung, and Blood Institute, Bethesda, Md; Division of Cardiothoracic Surgery, ${ }^{\mathrm{q}}$ Department of Surgery, Emory University, Atlanta, Ga; and Division of Critical Care Medicine, ${ }^{\mathrm{r}}$ Department of Pediatrics, Children's Hospital of Wisconsin, Milwaukee, Wis.

This study was supported by U01 grants from the National Heart, Lung, and Blood Institute (HL068269, HL068270, HL068279, HL068281, HL068285, HL068292, HL068290, HL068288, HL085057, HL109781, and HL109737). This work is solely the responsibility of the authors and does not necessarily represent the official views of the National Heart, Lung, and Blood Institute or the National Institutes of Health.

Disclosures: Authors have nothing to disclose with regard to commercial support. ClinicalTrials.gov number, NCT00115934.

Received for publication April 2, 2013; revisions received July 5, 2013; accepted for publication July 26, 2013; available ahead of print Sept 26, 2013.

Address for reprints: Steven M. Schwartz, MD, Department of Critical Care Medicine, The Hospital for Sick Children and the University of Toronto, Toronto, ON, Canada (E-mail: steven.schwartz@sickkids.ca).

$0022-5223 / \$ 36.00$

Copyright $(C) 2014$ by The American Association for Thoracic Surgery

http://dx.doi.org/10.1016/j.jtcvs.2013.07.063 


\section{Abbreviations and Acronyms \\ $\mathrm{AVV}=$ atrioventricular valve \\ HLHS = hypoplastic left heart syndrome \\ HR = hazard ratio \\ ICU = intensive care unit \\ $\mathrm{IQR}=$ interquartile range \\ LOS = length of stay \\ MBTS $=$ modified Blalock-Taussig shunt \\ PA = pulmonary artery \\ PVR = pulmonary vascular resistance \\ RVEDP $=$ right ventricular end-diastolic pressure \\ RVFAC $=$ right ventricular fractional area change \\ RVPAS $=$ right ventricle-to-pulmonary artery shunt \\ SVR = single-ventricle reconstruction}

there are relatively few complications. ${ }^{3-8}$ Despite the generally excellent results, there are several preoperative risk factors associated with prolonged LOS, hospital death, or failure of the cavopulmonary circulation to provide adequate oxygenation and/or acceptable hemodynamics. The most commonly identified risks include stenosis or distortion of the pulmonary arteries (PAs) or increased pulmonary vascular resistance (PVR), ${ }^{1,9-11}$ atrioventricular valve (AVV) regurgitation, ${ }^{10,12-14}$ and younger age at the time of the stage II procedure. ${ }^{13,15,16}$

The primary outcome in the single-ventricle reconstruction (SVR) trial was transplant-free survival at 12 months postrandomization between subjects with single right ventricle anomalies palliated with a right ventricle-to-pulmonary artery shunt (RVPAS) versus a modified Blalock-Taussig shunt (MBTS) at the Norwood procedure. ${ }^{17}$ Transplant-free survival 12 months after randomization was higher with the RVPAS, but the trial showed several significant differences between the 2 groups of Norwood survivors regarding potential risk factors for the stage 2 procedure. Specifically, PA size by angiography before the stage 2 procedure, as measured by the Nakata index, was significantly smaller in the RVPAS group (median, 99 [interquartile range $\{\mathrm{IQR}\}$, 63-150] vs 125 [88-166]), as was the diameter of the distal right PA (5.2 \pm 1.7 vs $6.3 \pm 2.0 \mathrm{~mm})$. PA interventions during the study period were more common in the RVPAS group $(49 \%$ vs $28 \%) .{ }^{17}$

The primary purpose of this analysis was to report hospital outcomes after the stage 2 procedure in the SVR cohort and compare these outcomes between subjects who received the RVPAS and those who received the MBTS. Because of the low expected mortality of the stage 2 procedure, the analyses focused predominantly on morbidity rather than mortality. Hospital LOS was the primary outcome, with the hypothesis that LOS would be longer in the RVPAS group based on the increased incidence of pulmonary artery problems previously reported in this cohort. A secondary aim of this analysis was to identify risk factors for longer LOS and in-hospital death during the stage 2 hospitalization.

\section{METHODS \\ Subjects}

Details of the SVR trial design have been reported. ${ }^{18}$ The Institutional Review Board or Research Ethics Board at each participating center approved the study protocol, and written informed consent was obtained from parents before trial enrollment. Subjects were recruited from 15 centers in North America participating in the National Heart, Lung, and Blood Institute-funded Pediatric Heart Network between May 2005 and July 2008. Inclusion criteria consisted of a diagnosis of HLHS or other single right ventricle anomaly and planned Norwood procedure. Exclusion criteria were preoperative identification of anatomy rendering either an MBTS or RVPAS technically impossible, and any major congenital or acquired extracardiac abnormality that could independently affect the likelihood of the subject meeting the primary outcome of transplant-free survival at 12 months postrandomization. Only subjects who survived to the stage 2 procedure are included in this analysis.

\section{Study Design and Measurements}

Shunt type was defined for this analysis as the shunt in place at the end of the Norwood procedure (nonintention to treat). Other than random assignment of shunt, all participants were managed according to the standard practices at their clinical centers.

The outcome variables for the primary analysis included hospital LOS (primary outcome), days receiving mechanical ventilation, intensive care unit (ICU) LOS, performance of concurrent surgical or interventional procedures at the time of the stage 2 procedure or during postoperative hospitalization that are not routinely part of the stage 2 operation, number of serious adverse events and complications, and death. Those subjects who died during the stage 2 hospitalization were excluded from the analyses of LOS. We then analyzed potential risk factors that might influence hospital LOS or in-hospital death. The factors considered in the risk factor analysis were restricted to those judged to be clinically relevant. A full list of candidate predictors can be found in the Table E1. For the purpose of this analysis, unplanned postoperative procedures were limited to major cardiovascular procedures and did not include procedures such as thoracentesis or chest tube placement, sternal debridement, or gastrostomy tube insertion. To examine the impact of 2 potentially important confounders (namely, missing data regarding PVR and subjects who were not discharged after the Norwood and before the stage 2 procedure), alternative risk factor models were created.

Protocol-driven echocardiograms were obtained at a scheduled outpatient visit before the stage 2 procedure. The echocardiograms were interpreted at a core laboratory (Medical College of Wisconsin, Milwaukee) to assess the degree of AVV regurgitation (none/mild/moderate/severe), right ventricular end-systolic volume, right ventricular end-diastolic volume, right ventricular fractional area change (RVFAC), and right ventricular ejection fraction. RVFAC was the primary measurement of right ventricular function used in further analyses. The rationale and detailed methods for echocardiographic assessment of RV volume and function in the SVR cohort have been detailed elsewhere. ${ }^{19}$

Cardiac catheterization was performed in most subjects before the stage 2 procedure as part of routine clinical care, and angiograms were interpreted at a core laboratory (Duke University, Durham, NC). Hemodynamic measurements, such as right ventricular end-diastolic pressure (RVEDP), and calculations, such as PVR, were reported by the enrolling center. Anatomic measurements, including PA size and stenoses, were determined by the core laboratory. Because data needed to calculate PVR were missing for many subjects, it was excluded from the primary 
multivariable analysis. Total lower lobe index was calculated as a measure of total PA size from direct measurements of the right and left lower lobe PA diameters. This measurement has been the best measure of PA growth, is less affected by surgery than other indexed measures of PA size, ${ }^{20}$ and was, therefore, used as the measurement of PA size for consideration of entry into the multivariable model.

In addition to the echocardiographic- and catheterization-based diagnoses of AVV regurgitation and PA stenosis, we recorded the clinical diagnoses of these conditions, which were based on the overall impression of the treating cardiology teams.

Socioeconomic status at the time of randomization was assigned in 2 ways: (1) using a US census-based score derived from 6 measures based on income, housing, and occupational-related features of the subject's census block $\operatorname{tract}^{21}$; and (2) the percentage lower than the federal poverty level in the subject's census block tract.

\section{Statistical Analyses}

Hospital LOS was defined by days from stage 2 procedure date (day 1 ) to discharge date. Descriptive statistics are presented as mean $\pm \mathrm{SD}$, medians with IQR, and percentages, as appropriate. Differences between those subjects who died versus those who survived to hospital discharge were determined with a $t$ test, a Wilcoxon rank-sum test, or a Fisher exact test. A univariate Cox regression model was used to identify associations between clinical factors and time to hospital discharge after the stage 2 procedure. Only those that were significant at $P \leq .20$ with respect to outcome were considered for inclusion in the multivariable model. The linearity of the covariates and the proportional hazards assumption were evaluated both graphically and statistically. Stepwise Cox regression selection was used in conjunction with bootstrapping (1000 samples) to obtain reliability estimates for each of the predictors. All terms in the final multivariable model have a $P<.05$ and have a reliability of greater than $50 \%$. The primary multivariable analysis was constructed using all cases with complete data. Two additional models were created; the first excluded 13 subjects who were not discharged between the Norwood and stage 2 operation and who have been previously described, ${ }^{22}$ and the second included PVR from the pre-stage 2 catheterization as a potential predictor. All analyses were conducted using SAS, version 9.2 (SAS Institute, Inc, Cary, NC), and SAS macros for bootstrapping estimates of reliability.

\section{RESULTS}

\section{Patient Population and Diagnoses}

There were 549 subjects who were randomized in the SVR trial and underwent the Norwood procedure (Figure 1). Subjects who died or were transplanted before the stage 2 procedure, those with interrupted inferior vena cava resulting in a Kawashima procedure as a second stage, those subjects with missing data, and 1 with an uncharacteristically late stage 2 procedure at 23 months of age were excluded from this analysis. The final cohort consisted of 393 subjects, and because of differential rates of attrition between randomization and the stage 2 procedure, 172 subjects had an MBTS and 221 had an RVPAS.

The cohort was $64 \%$ male and $81 \%$ white. Anatomy was predominantly HLHS (88\%). The most common associated diagnoses before the stage 2 procedure, as reported by the clinical teams, were branch PA stenosis $(26 \%)$ and AVV regurgitation $(12 \%)$. Mean right $(\mathrm{n}=189)$ and left $(\mathrm{n}=212)$ PA pressures at pre-stage 2 catheterization were $14.4 \pm 3.4$ and $14.7 \pm 3.8 \mathrm{~mm} \mathrm{Hg}$, respectively, and

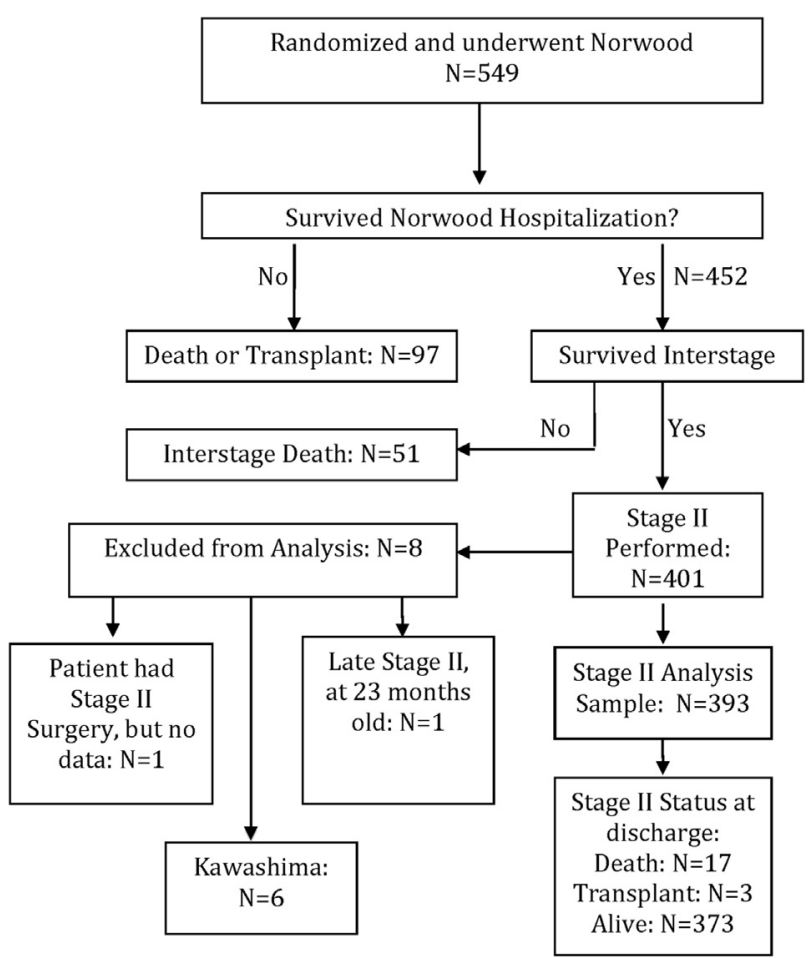

FIGURE 1. Flow diagram showing the single-ventricle reconstruction (SVR) trial cohort from inception through stage 2 hospitalization.

mean PVR $(\mathrm{n}=264)$ was $2.1 \pm 1.1$ Wood Units $\times \mathrm{m}^{2}$. Pre-stage 2 angiography revealed $17 \%$ of subjects to have $35 \%$ or greater stenosis of the left PA and $21 \%$ to have similar stenosis of the right PA. Echocardiography demonstrated at least moderate AVV regurgitation in $26 \%$ and a mean RVFAC of $34 \% \pm 8 \%$. Further details can be found in the Table E2.

Mean age at the time of the stage 2 procedure was $5.3 \pm$ 1.7 months. The stage 2 procedure was elective, as reported by the individual site investigators, in $66 \%$. The subjects who underwent stage 2 nonelectively were younger $(4.6 \pm$ 1.7 vs $5.6 \pm 1.5$ months; $P<.001$ ), and the average number of concurrent procedures was higher $(1.2 \pm 1.5$ vs $0.8 \pm 1.0$; $P<.001)$. Timing of the stage 2 procedure was not associated with shunt type (29\% MBTS vs $37.5 \%$ RVPAS were nonelective; $P=.86$ ). The most common reason for nonelective timing of the stage 2 procedure was progressive hypoxemia $(\mathrm{n}=107)$, with ventricular dysfunction $(\mathrm{n}=33)$, shunt stenosis or occlusion $(\mathrm{n}=17)$, aortic arch obstruction $(\mathrm{n}=13)$, failure to thrive $(\mathrm{n}=12)$, AVV regurgitation $(\mathrm{n}=12)$, and PA stenosis $(\mathrm{n}=5)$ accounting for almost all remaining nonelective stage 2 procedures.

A right bidirectional cavopulmonary anastomosis was the most common type of stage 2 procedure and was performed in $64 \%$ of subjects, with a right hemi-Fontan being the next most common at $24 \%$. Cardiopulmonary bypass time averaged $93 \pm 43$ minutes, and $73 \%$ of cases were performed without deep hypothermic circulatory 
TABLE 1. Subject and surgical characteristics at the time of stage 2 procedure

\begin{tabular}{|c|c|c|c|c|}
\hline & Overall $(\mathbf{n}=393)^{*}$ & Stage 2 mortality $(n=17)$ & Survivors $(n=373)$ & \\
\hline Characteristics & Mean \pm SD/No. $(\%)$ & Mean \pm SD/No. $(\%)$ & Mean \pm SD/No. $(\%)$ & $P$ value $\dagger$ \\
\hline Age at stage 2, mo & $5.3 \pm 1.7$ & $4.9 \pm 2.2$ & $5.3 \pm 1.6$ & .33 \\
\hline Weight-for-age z score $\ddagger$ & $-1.8 \pm 1.2$ & $-2.5 \pm 1.6(\mathrm{n}=15)$ & $-1.8 \pm 1.2(\mathrm{n}=368)$ & .02 \\
\hline Timing of stage 2 procedure & & & & .009 \\
\hline Elective & $260(66.2)$ & $6(35.3)$ & $252(67.6)$ & \\
\hline Nonelective & $133(33.8)$ & $11(64.7)$ & $121(32.4)$ & \\
\hline Type of stage 2 procedure & & & & .65 \\
\hline Bidirectional cavopulmonary shunt & $250(63.6)$ & $13(76.5)$ & $235(63.0)$ & \\
\hline Hemi-Fontan & $94(23.9)$ & $2(11.8)$ & $91(24.4)$ & \\
\hline Bilateral bidirectional cavopulmonary shunts & $42(10.7)$ & $2(11.8)$ & $40(10.7)$ & \\
\hline Other & $7(1.8)$ & $0(0.0)$ & $7(1.9)$ & \\
\hline \multicolumn{5}{|l|}{ Operative support } \\
\hline Total CPB time, min & $92.7 \pm 43.4$ & $134.1 \pm 43.7(n=16)$ & $90.4 \pm 42.1(\mathrm{n}=371)$ & $<.001$ \\
\hline DHCA & & & & .15 \\
\hline Yes & 105 (26.9) & $7(43.8)$ & $97(26.1)$ & \\
\hline No & $286(73.1)$ & $9(56.3)$ & 275 (73.9) & \\
\hline \multicolumn{5}{|l|}{ Concurrent procedures $\S$} \\
\hline Pulmonary artery repairs & $141(35.9)$ & $8(47.1)$ & $133(35.7)$ & .44 \\
\hline Atrioventricular valve repairs & $44(11.2)$ & $9(52.9)$ & $34(9.1)$ & $<.001$ \\
\hline Aortic arch repairs & $24(6.1)$ & $1(5.9)$ & $22(5.9)$ & 1.00 \\
\hline Other vascular repairs & $19(4.8)$ & $1(5.9)$ & 17 (4.6) & .56 \\
\hline Atrial septal interventions & $17(4.3)$ & $1(5.9)$ & $16(4.3)$ & .54 \\
\hline Aortic/neoaortic valve repair & $9(2.3)$ & $0(0.0)$ & $9(2.4)$ & 1.00 \\
\hline ECMO & $9(2.3)$ & $4(23.5)$ & $4(1.1)$ & $<.001$ \\
\hline EFE resection & $9(2.3)$ & 0 & $9(2.4)$ & 1.00 \\
\hline Arrhythmia intervention & $8(2.0)$ & $1(11.8)$ & $5(1.3)$ & .03 \\
\hline Airway procedure & $5(1.3)$ & 0 & $5(1.3)$ & 1.00 \\
\hline Intervention for ICU complication & $4(1.0)$ & $1(5.9)$ & $3(0.8)$ & .16 \\
\hline Atrial reduction & $3(0.8)$ & $3(17.7)$ & 0 & $<.001$ \\
\hline Other & $7(1.8)$ & $1(5.9)$ & $6(1.6)$ & .27 \\
\hline
\end{tabular}

Bold indicates $P<.05$. CPB, Cardiopulmonary bypass; $D H C A$, deep hypothermic circulatory arrest; $E C M O$, extracorporeal membrane oxygenation; $E F E$, endocardial fibroelastosis; $I C U$, intensive care unit; $S D$, standard deviation. * Overall cohort includes survivors $(\mathrm{n}=373)$, nonsurvivors $(\mathrm{n}=17)$, and transplants before discharge $(\mathrm{n}=3)$. $\dagger P$ values obtained from $t$-test, Wilcoxon rank-sum test, and Fisher exact test. Test of significant differences between in-hospital deaths and survivors, but not the transplants. $\ddagger$ From prestage 2 echocardiogram. $\S$ Includes postoperative procedures during stage 2 hospitalization.

arrest. Concurrent procedures not otherwise part of a usual stage 2 procedure or unplanned cardiovascular interventions before stage 2 hospital discharge were performed in $56 \%$ of subjects. The most common concurrent procedures were those involving PA plasty $(36 \%)$, followed by atrioventricular valve repair $(11 \%)$ and aortic arch repair $(6 \%)$ (Table 1).

\section{Stage 2 Morbidity Outcomes}

Outcomes by shunt type are summarized in Table 2 . Median hospital LOS was 8 days (IQR, 6-14 days). There were no differences in hospital LOS, ventilator days, ICU LOS, number of concurrent procedures, serious adverse events, or complications between subjects with an RVPAS and those with an MBTS.

\section{Univariate Analysis for LOS}

The analysis for the primary outcome was performed on a cohort of 372 subjects, which excluded 17 in-hospital deaths, 3 in-hospital heart transplants, and 1 subject with no information regarding discharge in the data set. The list of candidate predictors for hospital LOS after the stage 2 procedure and the univariate modeling results can be found in the Table E2.

\section{Multivariable Model for LOS}

Longer hospital LOS was independently associated $\left(\mathrm{R}^{2}=0.26\right)$ with center, longer post-Norwood LOS (hazard ratio [HR], 1.93 per log day; $P<.001$ ), nonelective timing for the stage 2 procedure (HR, $1.78 ; P<.001)$, and a clinical diagnosis of branch PA stenosis at the time of the stage 2 procedure (HR, 1.56; $P<.001)$ (Table 3). Shunt type was not significant when added to this model $(P=.92)$. An alternative analysis that excluded the 13 subjects who were not discharged from the hospital after the Norwood procedure showed the same associations as the primary model and an additional inverse association between RVFAC and post-stage II LOS (Table 4). A multivariable model $(\mathrm{N}=253)$ that excluded subjects in whom PVR could not be measured found the same significant risk 
TABLE 2. Outcomes by shunt type*

\begin{tabular}{|c|c|c|c|c|c|c|c|}
\hline & \multicolumn{2}{|c|}{ Overall $(\mathrm{N}=393)$} & \multicolumn{2}{|c|}{$\operatorname{MBTS}(n=172)$} & \multicolumn{2}{|c|}{$\operatorname{RVPAS}(\mathbf{n}=221)$} & \multirow[b]{2}{*}{$P$ value } \\
\hline & Mean \pm SD/No. $(\%)$ & $\begin{array}{c}\text { Median } \\
\text { (IQR) }\end{array}$ & Mean \pm SD/No. $(\%)$ & $\begin{array}{c}\text { Median } \\
\text { (IQR) }\end{array}$ & Mean \pm SD/No. $(\%)$ & $\begin{array}{c}\text { Median } \\
\text { (IQR) }\end{array}$ & \\
\hline No. of in-hospital deaths & $17(4.3)$ & & $7(4.1)$ & & $10(4.5)$ & & 1.00 \\
\hline No. of in-hospital transplants & $3(0.8)$ & & $1(0.6)$ & & $2(0.9)$ & & 1.00 \\
\hline Length of hospital stay, $d \ddagger$ & $13.9 \pm 17.0$ & $8(6-13)$ & $12.5 \pm 13.9$ & $8(6-11.5)$ & $15.0 \pm 19.1$ & $8(6-15.0)$ & .07 \\
\hline Total ventilated time, $\mathrm{d} \ddagger$ & $4.0 \pm 12.3$ & $2(1-3)$ & $3.1 \pm 5.7$ & $2(1-3)$ & $4.8 \pm 15.7$ & $2(1-3.5)$ & .34 \\
\hline Total ICU time, $\mathrm{d}_{\uparrow}^{\dagger}$ & $8.0 \pm 14.3$ & $4(3-7)$ & $7.2 \pm 10.8$ & $4(3-6)$ & $8.6 \pm 16.6$ & $4(3-8)$ & .11 \\
\hline No. of SAEs or complications & $1.2 \pm 2.5$ & $0(0-1)$ & $1.1 \pm 1.8$ & $0(0-2)$ & $1.3 \pm 3.0$ & $0(0-1)$ & .84 \\
\hline 0 & $210(53.4)$ & & $91(52.9)$ & & $119(53.8)$ & & .96 \\
\hline 1 & 85 (21.6) & & $37(21.5)$ & & $48(21.7)$ & & \\
\hline$\geq 2$ & $98(24.9)$ & & $44(25.6)$ & & $54(24.4)$ & & \\
\hline No. of concurrent procedures $\S$ & $0.9 \pm 1.2$ & $1(0-1)$ & $0.9 \pm 1.1$ & $1(0-1)$ & $0.9 \pm 1.3$ & $1(0-1)$ & .77 \\
\hline 0 & $174(44.3)$ & & $76(44.2)$ & & $98(44.3)$ & & .58 \\
\hline 1 & 147 (37.4) & & 68 (39.5) & & $79(35.8)$ & & \\
\hline$\geq 2$ & $72(18.3)$ & & $28(16.3)$ & & 44 (19.9) & & \\
\hline
\end{tabular}

MBTS, Modified Blalock-Taussig shunt; RVPAS, right ventricle-to-pulmonary artery shunt; $I Q R$, interquartile range; $I C U$, intensive care unit; $S A E$, serious adverse event; $S D$, standard deviation. *Refers to shunt type in place at the end of the Norwood procedure. $\dagger P$ values obtained from Wilcoxon rank-sum test and Fisher exact test. $\ddagger$ Excluding deaths and transplants. §Includes postoperative procedures during stage 2 hospitalization.

factors as the primary model, except that higher PVR (HR, 1.24 per 1 Wood Unit $\times \mathrm{M}^{2} ; P=.004$ ), instead of pulmonary artery stenosis, was associated with longer hospital LOS (Table 5). The incidence of $35 \%$ or greater branch stenosis was similar between those subjects with PVR reported and those for whom those data were missing (data not shown). Median hospital LOS was calculated for subgroups defined by the presence versus absence of all possible combinations of the 3 risk factors identified in the multivariable model (Table 6). A cut point of 24 days was used to define prolonged LOS after the Norwood operation, because this was the median LOS for transplant-free survivors who later underwent a stage 2 procedure. The median LOS after the stage 2 procedure was 6 days when no risk factors were present and 13 days when all 3 risk factors were present.

\section{Mortality}

Seventeen subjects (4\%) died after the stage 2 procedure and before hospital discharge. An additional 3

TABLE 3. Final model for risk factors associated with stage 2 hospital length of stay $\left(N=371\right.$, generalized $\left.R^{2}=0.26\right)$

\begin{tabular}{|c|c|c|c|}
\hline Variable & $\begin{array}{l}\text { Hazard ratio } \\
(\mathbf{9 5} \% \mathbf{C I}) \\
\end{array}$ & $P$ value & $\begin{array}{c}\text { Reliability, } \\
\% \\
\end{array}$ \\
\hline Site & & .002 & 97 \\
\hline $\begin{array}{l}\text { Log of Norwood length of } \\
\text { stay, } d\end{array}$ & $1.93(1.60-2.34)$ & $<.001$ & 99 \\
\hline $\begin{array}{l}\text { Nonelective reason for timing } \\
\text { of stage } 2\end{array}$ & $1.78(1.38-2.31)$ & $<.001$ & 78 \\
\hline $\begin{array}{l}\text { Associated clinical diagnosis } \\
\text { with stage 2: branch PA } \\
\text { stenosis present }\end{array}$ & $1.56(1.20-2.02)$ & $<.001$ & 64 \\
\hline
\end{tabular}

subjects $(1 \%)$ remained in the hospital until transplantation. Univariate comparison of those subjects who died or were transplanted during the stage 2 hospitalization with those subjects who survived to discharge without transplant is shown in Table 1. Characteristics associated with inhospital mortality or transplantation included longer Norwood LOS, not being discharged between the Norwood and stage 2 procedures, extracorporeal membrane oxygenation after the Norwood, nonelective timing of the stage 2 procedure, a clinical diagnosis of AVV regurgitation at the time of the stage 2 procedure, higher RVEDP at pre-stage 2 catheterization, lower weight-for-age $\mathrm{z}$ score at the time of the pre-stage 2 echocardiogram, moderate or greater AVV regurgitation on pre-stage 2 echocardiogram, longer total cardiopulmonary bypass time at the stage

TABLE 4. Final model for risk factors associated with stage 2 hospital length of stay excluding 13 subjects not discharged between Norwood and stage 2 procedures $\left(N=331\right.$, generalized $\left.R^{2}=0.24\right)$

\begin{tabular}{|c|c|c|c|}
\hline Variable & $\begin{array}{c}\text { Hazard ratio } \\
(95 \% \text { CI })\end{array}$ & $P$ value & $\begin{array}{c}\text { Reliability, } \\
\%\end{array}$ \\
\hline Site & & $<.001$ & 98 \\
\hline $\begin{array}{l}\text { Log of Norwood length of } \\
\text { stay, } d\end{array}$ & $1.56(1.25-1.96)$ & $<.001$ & 79 \\
\hline $\begin{array}{l}\text { Nonelective reason for } \\
\text { timing of stage } 2\end{array}$ & $1.88(1.42-2.50)$ & $<.001$ & 89 \\
\hline $\begin{array}{l}\text { Associated clinical diagnosis } \\
\text { with stage 2: branch PA } \\
\text { stenosis present }\end{array}$ & $1.60(1.22-2.10)$ & $<.001$ & 81 \\
\hline $\begin{array}{l}\text { Pre-stage } 2 \text { echo: RV } \\
\text { fractional area change } \\
\text { (range, } 0-1)^{*}\end{array}$ & $\begin{array}{l}0.91(0.85-0.98) \\
\text { per } 0.05 \text { increase }\end{array}$ & .017 & 54 \\
\hline
\end{tabular}


TABLE 5. Final model for risk factors associated with stage 2 hospital length of stay including only subjects for whom PVR calculations were available $\left(N=253\right.$, generalized $\left.R^{2}=0.28\right)$

\begin{tabular}{|c|c|c|c|}
\hline Variable & $\begin{array}{c}\text { Hazard ratio } \\
(\mathbf{9 5} \% \mathrm{CI})\end{array}$ & $P$ value & $\begin{array}{c}\text { Reliability, } \\
\%\end{array}$ \\
\hline Site & & .003 & 95 \\
\hline $\begin{array}{l}\text { Log of Norwood length } \\
\text { of stay, } d\end{array}$ & $1.84(1.48-2.30)$ & $<.001$ & 99 \\
\hline $\begin{array}{l}\text { Nonelective reason for } \\
\text { timing of stage } 2\end{array}$ & $1.51(1.09-2.09)$ & .013 & 62 \\
\hline $\begin{array}{l}\text { Pre-stage } 2 \text { catheterization } \\
\text { PVR, Wood units }\end{array}$ & $1.24(1.07-1.44)$ & .004 & 69 \\
\hline
\end{tabular}

2 procedure, and surgical atrioventricular valve repair during the stage 2 hospitalization. Among those with elective timing of the stage 2 procedure, there was no statistically significant relationship between age at the stage 2 procedure and death or transplant (data not shown). Because of the overall low in-hospital mortality/transplant rate, multivariable modeling was not performed.

\section{DISCUSSION}

Outcomes of stage 2 hospitalization for subjects enrolled in the Pediatric Heart Network-sponsored SVR trial were favorable and not associated with the type of shunt placed at the initial Norwood procedure. The median hospital LOS was 8 days, consistent with several previous singlecenter reports, ${ }^{5-8,12,23-25}$ although some series have reported considerably longer LOS, ranging from 11 to 21 days. ${ }^{13,26}$ Given this wide variability in LOS in the published literature, it is not surprising that there was a significant association of LOS with the surgical center at which the stage 2 procedure was performed.

Both anatomic and physiologic PA complications have been implicated as risk factors for worse stage 2 outcomes, including pulmonary vascular resistance of greater than 3 Wood Units $\times \mathrm{M}^{2}$ and PA distortion, ${ }^{1}$ although others have reported that PA augmentation does not increase mortality risk. ${ }^{2}$ More contemporary series suggest a greater adverse consequence of elevated PVR than PA stenosis, at

TABLE 6. Median stage 2 procedure LOS (days) by risk factor group

\begin{tabular}{llllc}
\hline $\begin{array}{c}\text { No. of risk } \\
\text { factors }\end{array}$ & $\begin{array}{c}\text { Norwood } \\
\text { LOS }>\text { 24 d }\end{array}$ & $\begin{array}{c}\text { Reason for } \\
\text { timing of stage } \\
\text { 2 procedure }\end{array}$ & $\begin{array}{c}\text { Diagnosis } \\
\text { of PA } \\
\text { stenosis }\end{array}$ & $\begin{array}{c}\text { Median stage } \\
\text { 2 procedure } \\
\text { LOS }\end{array}$ \\
\hline 0 (Best) & No & Elective & No & $6(\mathrm{n}=91)$ \\
1 & Yes & Elective & No & $8(\mathrm{n}=97)$ \\
1 & No & Nonelective & No & $8(\mathrm{n}=38)$ \\
1 & No & Elective & Yes & $8(\mathrm{n}=36)$ \\
2 & Yes & Elective & Yes & $9(\mathrm{n}=27)$ \\
2 & No & Nonelective & Yes & $9(\mathrm{n}=18)$ \\
2 & Yes & Nonelective & No & $14(\mathrm{n}=48)$ \\
3 (Worst) & Yes & Nonelective & Yes & $13(\mathrm{n}=16)$ \\
\hline
\end{tabular}

$L O S$, Length of stay (days); $P A$, pulmonary artery. least with respect to mortality before the Fontan operation. ${ }^{9,11,27}$ Regarding hospital LOS, Gray and colleagues ${ }^{26}$ found that the need to place a stent in the RVPAS before the stage 2 procedure was associated with a 10-day increase in LOS. The current study found that a clinical diagnosis of branch PA stenosis was the measurement most associated with increased hospital LOS, even more so than detailed angiographic measurements. This model did not include PVR because this measurement was obtained in only 253 of the 393 subjects in the cohort. When PVR was included in the model, branch PA stenosis was no longer associated with increased hospital LOS. PVR cannot be easily measured in subjects with significant branch PA stenosis, and it is, therefore, likely that the latter model excluded most subjects with significant branch PA stenosis. Furthermore, measures of total PA growth (Nakata index or the lower lobe index) were not associated with stage 2 mortality in a univariate analysis.

We hypothesized that the RVPAS group would have a longer hospital LOS because of smaller PA size and increased number of PA interventions between the Norwood and stage 2 procedures. Hospital LOS after the stage 2 procedure tended to be longer in the RVPAS group, although this did not reach statistical significance (mean, 15.0 vs 12.5 days; identical medians, 8 days; Wilcoxon $P=.07$ and Cox model for time to discharge $P=.14$ ). Therefore, it appears that it is really pulmonary artery anatomy rather than shunt type that is associated with stage 2 outcomes. Smaller series have shown no difference between the RVPAS and MBTS on outcomes at the stage 2 procedure, ${ }^{23,24}$ and Januszewska and colleagues ${ }^{28}$ reported a shorter ICU LOS with the RVPAS compared with the MBTS. Although our data suggest that it is PA abnormalities, rather than shunt type alone, that are associated with longer LOS, the RVPAS seems likely to be responsible for more PA abnormalities than the MBTS.

The finding that LOS after the stage 2 procedure is associated with a longer LOS after the Norwood procedure likely represents a surrogate for a multitude of other problems, such as ongoing heart failure from diminished ventricular function or AVV regurgitation, feeding difficulties, or other complications that result in morbidity. All of these variables were significantly associated with prolonged stage 2 hospital LOS in the univariate, but not the multivariable, analysis. Friedman and colleagues ${ }^{14}$ found that prolonged LOS after the Norwood procedure was associated with failure to complete the Fontan procedure, suggesting that these complications have longterm consequences in this population.

Similarly, the association of nonelective timing of the stage 2 procedure with longer stage 2 hospital LOS may reflect several anatomic and physiologic complications. Although age at procedure and weight $\mathrm{z}$-score were univariate predictors of LOS in the current study, they 
were not independent predictors of LOS. This finding is supported by the observations that subjects who underwent nonelective stage 2 were younger and more likely to have concurrent procedures. Several previous investigators have shown associations between younger age or smaller size and complications resulting in prolonged $\operatorname{LOS}^{8,15,24,29}$ or death ${ }^{16}$ after the stage 2 procedure. A comparison of those undergoing the stage 2 procedure at younger than 3 months of age with those who were 3 months or older did not identify an independent effect of age when other factors, such as preoperative PA pressure and AVV regurgitation, were taken into account. ${ }^{10}$

The stage 2 procedure in-hospital mortality rate in this multicenter cohort was $4 \%$, with an additional $1 \%$ of subjects undergoing heart transplantation before discharge. Most reports from single centers have indicated mortality rates of less than $2 \%$, and frequently less than $1 \%{ }^{4-7,12,25,28}$ Even those series limited to patients with HLHS $^{6,28}$ and, thus, anatomically similar to the current cohort have generally, although not universally, ${ }^{11}$ demonstrated lower hospital mortality than in the SVR cohort, and Scheurer and colleagues ${ }^{12}$ found that HLHS was not associated with any additional risk at the stage 2 procedure in a series of single-ventricle patients. An important difference between the SVR trial cohort and others is that the SVR cohort is an incident cohort and might, therefore, be more inclusive than single-center reports. Also, publication bias may favor lower mortality rates being published.

Several factors were associated with mortality in a univariate analysis. Of particular note is moderate or greater AVV regurgitation, whether noted on the pre-stage 2 echocardiogram or as a clinical diagnosis, AVV repair concurrent with the stage 2 procedure, and an increased RVEDP at the pre-stage 2 catheterization. AVV regurgitation has been identified as a risk for early ${ }^{10}$ and late ${ }^{12-14}$ mortality after the stage 2 procedure. Hypoplastic left heart syndrome patients with AVV regurgitation may be at higher risk than those with other types of singleventricle anatomy, ${ }^{29}$ although there are also reports that AVV regurgitation is not associated with in-hospital mortality at the stage $2^{2}$ or Fontan procedures, ${ }^{30}$ unlike the current results. Longer-term follow-up of the subjects in the SVR cohort who have undergone AVV repair will be important to determine if the strategy attempting repair of the moderate or severely regurgitant $\mathrm{AVV}$ at the time of the stage 2 procedure is ultimately successful.

There are several limitations to our investigation. Practice variation exists between centers, as was reflected by the significant association of center with hospital LOS. Furthermore, our multivariable model accounted for only $26 \%$ of the variance in LOS, suggesting that there are other important issues that affect individual patients and were not measured or analyzed herein despite the extensive nature of the SVR database. As previously discussed, many variables evaluated in this study may be confounded with others, such as age at stage 2 and nonelective timing for stage 2. Consequently, some variables deemed important in the multivariable models may only be surrogates for other unmeasured variables. By adjusting for site and using bootstrapping, we have tried to minimize bias and maximize reliability.

In conclusion, we found that the stage 2 procedure for HLHS and other single right ventricle anomalies is most commonly followed by a relatively short hospital course with a few clinically significant complications, and this is unrelated to the shunt type placed at the Norwood operation. Overall hospital mortality after the stage 2 procedure is low in this generally high-risk population, although the need for additional surgical and interventional procedures at the time of the stage 2 hospitalization is relatively high. Patients who require a nonelective stage 2 procedure, those with a diagnosis of branch PA stenosis, and those who had a prolonged LOS after the Norwood procedure are at significant risk for a prolonged hospital LOS after the stage 2 procedure.

\section{References}

1. Pridjian AK, Mendelsohn AM, Lupinetti FM, Beekman RH, Dick M, Serwer G, et al. Usefulness of the bidirectional Glenn procedure as staged reconstruction for the functional single ventricle. Am J Cardiol. 1993;71:959-62.

2. Forbess JM, Cook N, Serraf A, Burke RP, Mayer JE, Jonas RA. An institutional experience with second- and third-stage palliative procedures for hypoplastic left heart syndrome: the impact of the bidirectional cavopulmonary shunt. J Am Coll Cardiol. 1997;29:665-70.

3. Reddy VM, McElhinney DB, Moore P, Haas GS, Hanley FL. Outcomes after bidirectional cavopulmonary shunt in infants less than 6 months old J Am Coll Cardiol. 1997;29:1365-70.

4. Douglas WI, Goldberg CS, Mosca RS, Law IH, Bove EL. Hemi-Fontan procedure for hypoplastic left heart syndrome: outcome and suitability for Fontan. Ann Thorac Surg. 1999;68:1361-7.

5. Kogon BE, Plattner C, Leong T, Simsic J, Kirshbom PM, Kanter KR. The bidirectional Glenn operation: a risk factor analysis for morbidity and mortality. J Thorac Cardiovasc Surg. 2008;136:1237-42.

6. Azakie A, Johnson NC, Anagnostopoulos PV, Akram SM, McQuillen P, Sapru A. Stage II palliation of hypoplastic left heart syndrome without cardiopulmonary bypass. J Thorac Cardiovasc Surg. 2011;141:400-6.

7. Lapar DJ, Mery CM, Peeler BB, Kron IL, Gangemi JJ. Short and long-term outcomes for bidirectional glenn procedure performed with and without cardiopulmonary bypass. Ann Thorac Surg. 2012;94:164-70.

8. Menon SC, McCandless RT, Mack GK, Lambert LM, McFadden M, Williams RV, et al. Clinical outcomes and resource use for infants with hypoplas tic left heart syndrome during bidirectional Glenn: summary from the Joint Council for Congenital Heart Disease National Pediatric Cardiology Quality Improvement Collaborative Registry. Pediatr Cardiol. 2013;34:143-8.

9. Malhotra SP, Ivy DD, Mitchell MB, Campbell DN, Dines ML, Miyamoto S, et al Performance of cavopulmonary palliation at elevated altitude: midterm outcomes and risk factors for failure. Circulation. 2008;118(suppl):S177-81.

10. Petrucci O, Khoury PR, Manning PB, Eghtesady P. Outcomes of the bidirectiona Glenn procedure in patients less than 3 months of age. J Thorac Cardiovasc Surg. 2010;139:562-8.

11. Alsoufi B, Manlhiot C, Awan A, Alfadley F, Al-Ahmadi M, Al-Wadei A, et al. Current outcomes of the Glenn bidirectional cavopulmonary connection for single ventricle palliation. Eur J Cardiothorac Surg. 2012;42:42-9.

12. Scheurer MA, Hill EG, Vasuki N, Maurer S, Graham EM, Bandisode V, et al Survival after bidirectional cavopulmonary anastomosis: analysis of preoperative risk factors. J Thorac Cardiovasc Surg. 2007;134:82-9.

13. Hansen JH, Uebing A, Furck AK, Scheewe J, Jung O, Fischer G, et al Risk factors for adverse outcome after superior cavopulmonary anastomosis for hypoplastic left heart syndrome. Eur J Cardiothorac Surg. 2011;40:e43-9. 
14. Friedman KG, Salvin JW, Wypij D, Gurmu Y, Bacha EA, Brown DW, et al. Risk factors for failed staged palliation after bidirectional Glenn in infants who have undergone stage one palliation. Eur J Cardiothorac Surg. 2011;40: 1000-6.

15. Jaquiss RDB, Ghanayem NS, Hoffman GM, Fedderly RT, Cava JR, Mussatto KA, et al. Early cavopulmonary anastomosis in very young infants after the Norwood procedure: impact on oxygenation, resource utilization, and mortality. J Thorac Cardiovasc Surg. 2004;127:982-9.

16. Nicolas RT, Hills C, Moller JH, Huddleston CB, Johnson MC. Early outcome after Glenn shunt and Fontan palliation and the impact of operation during viral respiratory season: analysis of a 19-year multi-institutional experience. Ann Thorac Surg. 2005;79:613-7.

17. Ohye RG, Sleeper LA, Mahony L, Newburger JW, Pearson GD, Lu M, et al. Comparison of shunt types in the Norwood procedure for single-ventricle lesions. N Engl J Med. 2010;362:1980-92.

18. Ohye RG, Gaynor JW, Ghanayem NS, Goldberg CS, Laussen PC, Frommelt PC, et al. Design and rationale of a randomized trial comparing the Blalock-Taussig and right ventricle-pulmonary artery shunts in the Norwood procedure. J Thorac Cardiovasc Surg. 2008;136:968-75.

19. Frommelt PC, Guey LT, Minich LL, Bhat M, Bradley TJ, Colan SD, et al. Does initial shunt type for the Norwood procedure affect echocardiographic measures of cardiac size and function during infancy? the Single Ventricle Reconstruction trial. Circulation. 2012;125:2630-8.

20. Reddy VM, McElhinney DB, Moore P, Petrossian E, Hanley FL. Pulmonary artery growth after bidirectional cavopulmonary shunt: is there a cause for concern? J Thorac Cardiovasc Surg. 1996;112:1180-90.

21. Diez Roux AV, Merkin SS, Arnett D, Chambless L, Massing M, Nieto FJ, et al Neighborhood of residence and incidence of coronary heart disease. $N$ Engl J Med. 2001;345:99-106.

22. Ghanayem NS, Allen KR, Tabbutt S, Atz AM, Clabby ML, Cooper DS, et al. Interstage mortality after the Norwood procedure: results of the multicenter
Single Ventricle Reconstruction trial. J Thorac Cardiovasc Surg. 2012;144: 896-906.

23. Ballweg JA, Dominguez TE, Ravishankar C, Kreutzer J, Marino BS, Bird GL, et al. A contemporary comparison of the effect of shunt type in hypoplastic left heart syndrome on the hemodynamics and outcome at stage 2 reconstruction. J Thorac Cardiovasc Surg. 2007;134:297-303.

24. Lai L, Laussen PC, Cua CL, Wessel DL, Costello JM, del Nido PJ, et al. Outcomes after bidirectional Glenn operation: Blalock-Taussig shunt versus right ventricle-to-pulmonary artery conduit. Ann Thorac Surg. 2007;83:1768-73.

25. Tanoue Y, Kado H, Boku N, Tatewaki H, Nakano T, Fukae K, et al. Three hundred and thirty-three experiences with the bidirectional Glenn procedure in a single institute. Interact Cardiovasc Thorac Surg. 2007;6:97-101.

26. Gray RG, Minich LL, Weng HY, Heywood MC, Burch PT, Cowley CG. Effect of endovascular stenting of right ventricle to pulmonary artery conduit stenosis in infants with hypoplastic left heart syndrome on stage II outcomes. Am J Cardiol. 2012;110:118-23.

27. Hussain A, Arfi AM, Hussamuddin M, Haneef AA, Jamjoom A, Al-Ata J, et al. Comparative outcome of bidirectional Glenn shunt in patients with pulmonary vascular resistance $>$ or $=3.5$ woods units versus $<3.5$ woods units. Am J Cardiol. 2008;102:907-12.

28. Januszewska K, Kołcz J, Mroczek T, Procelewska M, Malec E. Right ventricle-to-pulmonary artery shunt and modified Blalock-Taussig shunt in preparation to hemi-Fontan procedure in children with hypoplastic left heart syndrome. Eur J Cardiothorac Surg. 2005;27:956-61.

29. Anderson JB, Beekman RH, Border WL, Kalkwarf HJ, Khoury PR, Uzark K, et al. Lower weight-for-age z score adversely affects hospital length of stay after the bidirectional Glenn procedure in 100 infants with a single ventricle. J Thorac Cardiovasc Surg. 2009;138:397-404.

30. Kerendi F, Kramer ZB, Mahle WT, Kogon BE, Kanter KR, Kirshbom PM. Perioperative risks and outcomes of atrioventricular valve surgery in conjunction with Fontan procedure. Ann Thorac Surg. 2009;87:1484-8. 
TABLE E1. Cox regression model for predictors of length of hospital stay

\begin{tabular}{|c|c|c|c|}
\hline Variable & No. & $\begin{array}{c}\text { Hazard ratio } \\
(95 \% \mathbf{C I})\end{array}$ & $P$ value \\
\hline Center & 372 & & .004 \\
\hline \multicolumn{4}{|l|}{ Demographics } \\
\hline \multicolumn{4}{|l|}{ Sex } \\
\hline Male & 238 & $1.05(0.85-1.30)$ & .62 \\
\hline Female & 135 & Reference & \\
\hline \multicolumn{4}{|l|}{ Hispanic } \\
\hline Yes & 69 & $1.27(0.97-1.65)$ & .08 \\
\hline No & 300 & Reference & \\
\hline Race & & & .27 \\
\hline White & 304 & Reference & \\
\hline Black & 51 & $0.79(0.59-1.06)$ & \\
\hline Other & 14 & $1.09(0.63-1.88)$ & \\
\hline SES score & 360 & $0.98(0.96-1.00)$ & .09 \\
\hline Genetic syndrome & & & .02 \\
\hline Yes & 91 & Reference & \\
\hline No & 196 & $0.79(0.59-1.06)$ & \\
\hline Unknown & 85 & $1.09(0.63-1.88)$ & \\
\hline \multicolumn{4}{|l|}{ Anatomy } \\
\hline HLHS & & & .88 \\
\hline Yes & 333 & $1.03(0.74-1.43)$ & \\
\hline No & 40 & Reference & \\
\hline \multicolumn{4}{|l|}{$\begin{array}{c}\text { Clinical diagnoses at time } \\
\text { of stage } 2 \text { procedure }\end{array}$} \\
\hline Branch PA stenosis & & & .16 \\
\hline Yes & 97 & $1.18(0.94-1.49)$ & \\
\hline No & 274 & Reference & \\
\hline AVVR & & & .003 \\
\hline Yes & 37 & $1.69(1.20-2.39)$ & \\
\hline No & 334 & Reference & \\
\hline Aortic arch obstruction & & & .53 \\
\hline Yes & 28 & $1.13(0.77-1.67)$ & \\
\hline No & 343 & Reference & \\
\hline \multicolumn{4}{|l|}{ Norwood hospitalization } \\
\hline $\begin{array}{l}\text { Shunt type at the end of } \\
\text { Norwood }\end{array}$ & & & .14 \\
\hline MBTS & 164 & Reference & \\
\hline RVPAS & 208 & $1.17(0.95-1.44)$ & \\
\hline $\begin{array}{l}\text { Log-transformed } \\
\text { Norwood LOS }\end{array}$ & 372 & $1.80(1.53-2.13)$ & $<.001$ \\
\hline $\begin{array}{c}\text { Discharge after } \\
\text { Norwood } \\
\text { operation }\end{array}$ & & & $<.001$ \\
\hline No & 13 & $4.13(2.29-7.44)$ & \\
\hline Yes & 359 & Reference & \\
\hline On ECMO & & & .03 \\
\hline Yes & 25 & $1.64(1.07-2.52)$ & \\
\hline No & 348 & Reference & \\
\hline \multicolumn{4}{|l|}{ Interstage interventions } \\
\hline \multicolumn{4}{|l|}{ ECMO } \\
\hline Yes & 5 & $1.42(0.58-3.43)$ & .44 \\
\hline No & 368 & Reference & \\
\hline
\end{tabular}

TABLE E1. Continued

\begin{tabular}{|c|c|c|c|}
\hline Variable & No. & $\begin{array}{c}\text { Hazard ratio } \\
(95 \% \mathbf{C I})\end{array}$ & $P$ value \\
\hline $\begin{array}{l}\text { Interstage intervention } \\
\text { on aorta }\end{array}$ & & & .543 \\
\hline Yes & 62 & $1.09(0.83-1.43)$ & \\
\hline No & 310 & Reference & \\
\hline $\begin{array}{l}\text { Interstage intervention } \\
\text { on PA }\end{array}$ & & & .95 \\
\hline Yes & 10 & $1.02(0.54-1.91)$ & \\
\hline No & 362 & Reference & \\
\hline $\begin{array}{c}\text { Interstage intervention } \\
\text { on atrial septum }\end{array}$ & & & .66 \\
\hline Yes & 10 & $0.87(0.46-1.63)$ & \\
\hline No & 362 & Reference & \\
\hline $\begin{array}{l}\text { Other interstage } \\
\text { intervention }\end{array}$ & & & .89 \\
\hline Yes & 31 & $1.03(0.71-1.48)$ & \\
\hline No & 341 & Reference & \\
\hline \multicolumn{4}{|l|}{$\begin{array}{l}\text { Pre-stage } 2 \\
\text { cathetherization/ } \\
\text { echocardiogram }\end{array}$} \\
\hline RVFAC (range, 0-1) & 344 & $\begin{array}{c}0.93(0.87-1.003) \text { per } \\
0.05 \text {-unit increase }\end{array}$ & .06 \\
\hline $\begin{array}{l}\geq \text { Moderate tricuspid } \\
\text { valve regurgitation }\end{array}$ & 365 & & \\
\hline Yes & 86 & $1.52(1.19-1.95)$ & .001 \\
\hline No & 279 & Reference & \\
\hline \multicolumn{4}{|l|}{$\begin{array}{l}\text { Pre-stage } 2 \\
\text { catheterization } \\
\text { hemodynamics }\end{array}$} \\
\hline $\begin{array}{l}\text { Ventricular } \\
\text { end-diastolic } \\
\text { pressure from } \\
\text { cathetherization, mm } \\
\mathrm{Hg}\end{array}$ & 348 & $1.03(1.00-1.06)$ & .08 \\
\hline $\begin{array}{l}\text { Pulmonary vascular } \\
\text { resistance, Wood } \\
\text { units }\end{array}$ & 253 & $1.21(1.07-1.35)$ & .001 \\
\hline \multicolumn{4}{|l|}{ Pre-stage 2 angiography } \\
\hline $\begin{array}{l}\text { Severity of LPA } \\
\text { stenosis, \% }\end{array}$ & 325 & $1.00(0.99-1.00)$ & .64 \\
\hline$<15$ & 196 & $1.16(0.72-1.89)$ & .73 \\
\hline $15-<35$ & 75 & $1.04(0.62-1.74)$ & \\
\hline $35-<50$ & 36 & $1.25(0.71-2.21)$ & \\
\hline$\geq 50$ & 18 & Reference & \\
\hline $\begin{array}{r}\text { Severity of RPA } \\
\text { stenosis, \% }\end{array}$ & 325 & $1.16(0.72-1.89)$ & .13 \\
\hline$<15$ & 175 & $1.04(0.62-1.74)$ & .21 \\
\hline $15-<35$ & 80 & $1.25(0.71-2.21)$ & \\
\hline $35-<50$ & 40 & $1.16(0.72-1.89)$ & \\
\hline$\geq 50$ & 30 & Reference & \\
\hline $\begin{array}{l}\text { Total lower lobe index, } \\
\mathrm{mm}^{2} / \mathrm{M}^{2} *\end{array}$ & 322 & $\begin{array}{c}0.94(0.89-0.989) \text { per a } \\
\text { 50-unit increase }\end{array}$ & .02 \\
\hline Nakata index & 322 & $\begin{array}{c}0.96(0.90-1.03) \text { per a } \\
50 \text {-unit increase }\end{array}$ & .27 \\
\hline
\end{tabular}


TABLE E1. Continued

\begin{tabular}{|c|c|c|c|}
\hline Variable & No. & $\begin{array}{c}\text { Hazard ratio } \\
(95 \% \mathrm{CI})\end{array}$ & $P$ value \\
\hline \multicolumn{4}{|l|}{ At stage 2} \\
\hline $\begin{array}{l}\text { Reasons for timing of } \\
\text { stage } 2 \text { procedure }\end{array}$ & & & $<.001$ \\
\hline Elective & 252 & $0.61(0.49-0.77)$ & \\
\hline Nonelective & 120 & Reference & \\
\hline Age at stage 2 & & $0.96(0.90-1.01)$ & .11 \\
\hline $\begin{array}{l}\text { Weight-age } \mathrm{z} \text { score on } \\
\text { pre-stage } 2 \text { echo }\end{array}$ & 368 & $0.89(0.81-0.97)$ & .009 \\
\hline Type of stage 2 & & & .81 \\
\hline $\begin{array}{l}\text { Bidirectional } \\
\text { cavopulmonary } \\
\text { shunt }\end{array}$ & 234 & $0.85(0.40-1.80)$ & \\
\hline Hemi-Fontan & 91 & $0.84(0.39-1.81)$ & \\
\hline $\begin{array}{l}\text { Bidirectional } \\
\text { cavopulmonary } \\
\text { anastomoses }\end{array}$ & 40 & $0.73(0.33-1.64)$ & \\
\hline Other & 7 & Reference & \\
\hline $\begin{array}{l}\text { Total CPB time, per } \\
\text { 10-min increase }\end{array}$ & 370 & $1.05(1.02-1.08)$ & $<.001$ \\
\hline On DHCA & 371 & & .56 \\
\hline Yes & & $1.07(0.85-1.35)$ & \\
\hline No & & Reference & \\
\hline $\begin{array}{l}\text { Concurrent procedures: } \\
\text { PA repair }\end{array}$ & 372 & & .01 \\
\hline Yes & 133 & $1.32(1.06-1.63)$ & \\
\hline No & 239 & Reference & \\
\hline $\begin{array}{c}\text { Concurrent procedures: } \\
\text { aortic arch repair }\end{array}$ & 372 & & .09 \\
\hline Yes $(n=22)$ & 22 & $1.46(0.95-2.25)$ & \\
\hline No $(\mathrm{n}=350)$ & 350 & Reference & \\
\hline $\begin{array}{c}\text { Concurrent procedures: } \\
\text { AV valve repair }\end{array}$ & 372 & & .03 \\
\hline Yes & 34 & $1.49(1.04-2.12)$ & \\
\hline No & 338 & Reference & \\
\hline $\begin{array}{r}\text { Concurrent procedures: } \\
\text { aortic valve repair }\end{array}$ & 372 & & .48 \\
\hline Yes & 9 & $0.79(0.41-1.53)$ & \\
\hline No & 363 & Reference & \\
\hline Concurrent: ASD & 372 & & .73 \\
\hline Yes & 16 & $0.92(0.55-1.51)$ & \\
\hline No & 356 & Reference & \\
\hline
\end{tabular}

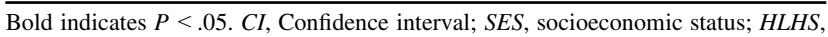
hypoplastic left heart syndrome; $P A$, pulmonary artery; $A V V R$, atrioventricular valve regurgitation; MBTS, modified Blalock-Taussig shunt; RVPAS, right ventricle-topulmonary artery shunt; $L O S$, length of hospital stay; ECMO, extracorporeal membrane oxygenation; $R V F A C$, right ventricle fractional area change; $L P A$, left pulmonary artery; $R P A$, right pulmonary artery; $C P B$, cardiopulmonary bypass; $D H C A$, deep hypothermic circulatory arrest; $A V$, atrioventricular; $A S D$, atrial septal defect. *Total lower lobe index was defined as follows: $3.14 \times$ (right lower lobe diameter $/ 2)^{2}+3.14 \times\left([\text { left lower lobe diameter } / 2]^{2}\right) /$ body surface area. 
TABLE E2. Characteristics of the analytic cohort of subjects undergoing the stage 2 procedure

\begin{tabular}{|c|c|c|c|c|}
\hline & Overall $(\mathbf{N}=393)^{*}$ & Stage 2 mortality $(n=17)$ & $\begin{array}{c}\text { Nontransplant } \\
\text { survivors }(n=373) \\
\end{array}$ & \\
\hline Characteristics & Mean \pm SD/No. $(\%)$ & Mean \pm SD/No. $(\%)$ & Mean \pm SD/No. $(\%)$ & $P$ value \\
\hline \multicolumn{5}{|l|}{ Demographics } \\
\hline Male & $250(63.6)$ & $11(64.7)$ & $238(63.8)$ & 1.00 \\
\hline Hispanic & & & & .32 \\
\hline Yes & $70(18.1)$ & $1(6.7)$ & $69(18.7)$ & \\
\hline No & 317 (81.9) & $14(93.3)$ & $300(81.3)$ & \\
\hline Unknown & 6 & 2 & 4 & \\
\hline Race & & & & .10 \\
\hline White & $317(81.3)$ & $11(64.7)$ & $304(82.2)$ & \\
\hline Black & $58(14.9)$ & $5(29.4)$ & $52(14.1)$ & \\
\hline Other & $15(3.9)$ & $1(5.9)$ & $14(3.8)$ & \\
\hline Unknown & 3 & 0 & 3 & \\
\hline SES score & $0.4 \pm 5.1$ & $0.4 \pm 3.6$ & $0.4 \pm 5.1$ & .97 \\
\hline Genetic syndrome/other anomalies & & & & .005 \\
\hline Yes & $93(23.7)$ & $1(5.9)$ & $91(24.4)$ & \\
\hline No & $204(51.9)$ & $6(35.3)$ & $196(52.5)$ & \\
\hline Unknown & $96(24.4)$ & $10(58.8)$ & $86(23.1)$ & \\
\hline \multicolumn{5}{|l|}{ Anatomy } \\
\hline HLHS & $346(88.0)$ & $11(64.7)$ & $333(89.3)$ & .009 \\
\hline \multicolumn{5}{|l|}{ Clinical diagnoses at time of stage 2 procedure $\ddagger$} \\
\hline Branch PA stenosis present & $102(26.1)$ & $4(25.0)$ & $98(26.3)$ & 1.00 \\
\hline AVVR & $45(11.5)$ & $8(50.0)$ & $37(10.0)$ & $<.001$ \\
\hline Aortic arch obstruction & $30(7.7)$ & $1(6.3)$ & $28(7.5)$ & 1.00 \\
\hline \multicolumn{5}{|l|}{ Norwood hospitalization } \\
\hline Shunt type at the end of Norwood & & & & 1.00 \\
\hline MBTS & $172(43.8)$ & $7(41.2)$ & $164(44.0)$ & \\
\hline RVPAS & $221(56.2)$ & $10(58.8)$ & $209(56.0)$ & \\
\hline Length of Norwood hospitalization, $d$ & $\begin{array}{r}33.8 \pm 30.8 ; \text { median } \\
(\text { IQR), } 24(17-39)\end{array}$ & $\begin{array}{r}72.2 \pm 51.7 \\
\text { median, } 61\end{array}$ & $31.9 \pm 28.3 ;$ median, 24 & $<.001$ \\
\hline Not discharged after Norwood & $22(5.6)$ & $8(47.1)$ & $13(3.5)$ & $<.001$ \\
\hline ECMO during Norwood hospitalization & $32(8.1)$ & $6(35.3)$ & $25(6.7)$ & .001 \\
\hline \multicolumn{5}{|l|}{ Interstage interventions } \\
\hline ECMO & $5(1.3)$ & 0 & $5(1.3)$ & 1.00 \\
\hline Intervention on aorta & $68(17.3)$ & $4(23.5)$ & $63(16.9)$ & .51 \\
\hline Intervention on PA & $10(2.5)$ & $0(0.0)$ & $10(2.7)$ & 1.00 \\
\hline Intervention on atrial septum & $10(2.5)$ & $0(0.0)$ & $10(2.7)$ & 1.00 \\
\hline Other interventions & $32(8.1)$ & $1(5.9)$ & $31(8.3)$ & 1.00 \\
\hline \multicolumn{5}{|l|}{ Pre-stage 2 echocardiography } \\
\hline RVFAC & $0.34 \pm 0.08(\mathrm{n}=363)$ & $0.31 \pm 0.06(\mathrm{n}=16)$ & $0.34 \pm 0.08(\mathrm{n}=344)$ & .17 \\
\hline$\geq$ Moderate tricuspid valve regurgitation & & & & $<.001$ \\
\hline Yes & $100(26.0)$ & $12(75.0)$ & $86(23.6)$ & \\
\hline No & $284(74.0)$ & $4(25.0)$ & $279(76.4)$ & \\
\hline \multicolumn{5}{|l|}{ Catheterization hemodynamics } \\
\hline RVEDP, mm Hg & $8.3 \pm 3.3(\mathrm{n}=366)$ & $10.8 \pm 3.5(\mathrm{n}=16)$ & $8.1 \pm 3.2(\mathrm{n}=348)$ & .001 \\
\hline PVR, Woods units & $2.1 \pm 1.1(\mathrm{n}=264)$ & $1.9 \pm 0.7(\mathrm{n}=10)$ & $2.1 \pm 1.2(\mathrm{n}=253)$ & .61 \\
\hline Transpulmonary gradient, $\mathrm{mm} \mathrm{Hg}$ & $4.9 \pm 3.1(\mathrm{n}=159)$ & $5.2 \pm 2.4(\mathrm{n}=7)$ & $4.8 \pm 3.1(\mathrm{n}=150)$ & .76 \\
\hline \multicolumn{5}{|l|}{ Angiography } \\
\hline $\begin{array}{l}\text { LPA stenosis at site of maximal stenosis } \\
\quad \text { (relative to proximal left lower diameter), } \%\end{array}$ & $\begin{array}{c}14.4 \pm 18.9(\mathrm{n}=336) \\
\text { median }(\mathrm{IQR}) \\
2.0(0.0-26.5)\end{array}$ & $18.2 \pm 21.9(\mathrm{n}=11)$ & $14.3 \pm 18.8(\mathrm{n}=325)$ & .50 \\
\hline$<15$ & $202(60.1)$ & $6(54.5)$ & $196(60.3)$ & .62 \\
\hline $15-\leq 35$ & $77(22.9)$ & $2(18.2)$ & $75(23.1)$ & \\
\hline $35-\leq 50$ & $38(11.3)$ & $2(18.2)$ & $36(11.1)$ & \\
\hline$>50$ & $19(5.7)$ & $1(9.1)$ & $18(5.5)$ & \\
\hline
\end{tabular}


TABLE E2. Continued

\begin{tabular}{|c|c|c|c|c|}
\hline & Overall $(\mathbf{N}=393)^{*}$ & $\underline{\text { Stage } 2 \text { mortality }(n=17)}$ & $\begin{array}{c}\text { Nontransplant } \\
\text { survivors }(\mathbf{n}=\mathbf{3 7 3})\end{array}$ & \\
\hline Characteristics & Mean \pm SD/No. $(\%)$ & Mean \pm SD/No. $(\%)$ & Mean \pm SD/No. $(\%)$ & $\boldsymbol{P}$ value $\dagger$ \\
\hline $\begin{array}{l}\text { RPA stenosis at site of maximal stenosis (relative } \\
\text { to proximal right lower diameter), } \%\end{array}$ & $\begin{array}{c}18.2 \pm 20.6(\mathrm{n}=337) \\
\text { median }(\mathrm{IQR}) \\
10.0(0.0-33.0)\end{array}$ & $22.0 \pm 19.1(\mathrm{n}=11)$ & $18.1 \pm 20.6(\mathrm{n}=325)$ & .54 \\
\hline$<15$ & $180(53.4)$ & $4(36.4)$ & $175(53.8)$ & .45 \\
\hline $15-\leq 35$ & $85(25.2)$ & $5(45.5)$ & $80(24.6)$ & \\
\hline $35-\leq 50$ & $41(12.2)$ & $1(9.1)$ & $40(12.3)$ & \\
\hline$>50$ & $31(9.2)$ & $1(9.1)$ & $30(9.2)$ & \\
\hline Total lower lobe index, $\mathrm{mm}^{2} / \mathrm{M}^{2} \S$ & $167.0 \pm 90.0(\mathrm{n}=333)$ & $169.5 \pm 72.2(\mathrm{n}=11)$ & $167.0 \pm 90.6(\mathrm{n}=322)$ & .93 \\
\hline Nakata index & $128.5 \pm 81.0(\mathrm{n}=333)$ & $114.3 \pm 53.7(\mathrm{n}=11)$ & $129.0 \pm 81.8(\mathrm{n}=322)$ & .56 \\
\hline
\end{tabular}

Bold indicates $P<.05$. SES, Socioeconomic status; HLHS, hypoplastic left heart syndrome; $P A$, pulmonary artery; AVVR, atrioventricular valve regurgitation; $M B T S$, modified Blalock-Taussig shunt; RVPAS, right ventricle-to-pulmonary artery shunt; $I Q R$, interquartile range; $E C M O$, extracorporeal membrane oxygenation; RVFAC, right ventricular fractional area change; $R V E D P$, right ventricular end-diastolic pressure; $P V R$, pulmonary vascular resistance; $L P A$, left pulmonary artery; $R P A$, right pulmonary artery; $S D$, standard deviation. *Overall cohort includes survivors $(\mathrm{n}=373)$, nonsurvivors $(\mathrm{n}=17)$, and transplants before discharge $(\mathrm{n}=3)$. $\dagger P$ values obtained from $t$-test, Wilcoxon rank-sum test, and Fisher exact test. Test of significant differences between in-hospital deaths and survivors, but not the transplants. $\ddagger$ As designated by overall clinical evaluation. §Total lower lobe index was defined as follows: $3.14 \times(\text { right lower lobe diameter/2 })^{2}+3.14 \times\left[\left(\right.\right.$ left lower lobe diameter/2) $\left.{ }^{2}\right] /$ body surface area. 